\title{
THE MEASUREMENT AND ASSESSMENT OF QUALITY IN AGRICULTURAL RESEARCH INSTITUTIONS
}

\author{
G. S. SOUZA*,**, E. R. CRUZ*, T. R. QUIRINO* \\ * Brazilian Corporation for Agricultural Research, SAIN W3-North Final, \\ Brasília (Brasil) $70770-900$ \\ ** Department of Statistics, University of Brasilia, \\ Brasília (Brasil) 70910-900
}

(Received March 29, 1993)

\begin{abstract}
We present the measure of quality introduced by the review team of Embrapa to evaluate its research projects. The quality measurement scheme comprises four different dimensions (External Validity, Internal Validity, Institutional Adequacy, and Formal Adequacy). The quality measurements are used as dependent variables in a multivariate effort to identify important factors necessary to improve overall as well as specific quality aspects.
\end{abstract}

\section{Introduction}

Recently, Embrapa (Brazilian Corporation for Agriculture Research), affiliated to the Ministry of Agriculture, undertook an extensive review program. The idea backing the review was to evaluate the impact of agricultural research activities in Brazil and to assess the adequacy, past and present, of Embrapa's research program to the demands of society.

In a rapidly changing political and social environment, both locally and at the world level, a review exercise is of fundamental importance to the establishment of strategic plants that will be the basis to continuously adapt Embrapa's research activities to the expectations of both government and society as a whole. According to modern management literature ${ }^{1}$, this attitude is crucial to the survival of the institution.

An important dimension of Embrapa's review was the evaluation of its research projects in regard to quality. This paper describes the measure of quality adopted to judge these research projects and the approaches used to assess the dependency of quality measurements on several input factors of administrative interest. The emphasis is on quantitative aspects. Social as well as political issues which have been implied by the analysis set forth here are discussed elsewhere6, ?. Our discussion 
proceeds as follows. In Section 2 we present the general aspects of the quality program and introduce the notion of quality used in the evaluation process. In Section 3 we define the input dimensions relative to which several quality dimensions are to be assessed. The dependency of quality on these independent variables are then statistically examined. Finally, in Section 4 a summary is presented with the main conclusions of the previous sections.

\section{The measurement of quality}

Ongoing research projects in Embrapa during the evaluation period (November, 1990) were subject to the control of three distinct administration entities. Firstly, and most basically, there is the figure of the Project Leader, primarily responsible for the existence of the research project and its execution and performance. Secondly, there is the figure of the Technical Director, responsible for the supervision of research projects within a given research center. Actually, Embrapa has 41 such centers spread all over Brazil. Thirdly, and lastly, there is the figure of the National Program Coordinator, responsible for the supervision of all projects within a national research program. Embrapa has about 60 such programs. A national research program comprises research projects that may be under the execution responsibility of distinct research centers and therefore under the local supervision of distinct Technical Directors. A Technical Director may or may not accumulate the task of a National Program Coordinator. At this point it is important to emphasize that, although actually suffering fundamental changes as a consequence of the review, all research activities in Embrapa's recent past were planned and carried out in terms of national research programs.

From the above context, at least in principle, and from the administrative point of view, three facts emerge. First, National Program Coordinators are the natural source of information in regard to the quality and adequacy of the administrative aspects of research projects. Second, the more technical aspects of the quality dimension are better judged by Technical Directors. Finally, the relative importance of potential factor inputs to affect quality in general are conveniently appraised via Project Leaders since the ultimate impact of cutbacks in resources is on the research project. With this background, three types of questionnaires, one adequate to each entity (National Program Coordinator, Technical Director, and Project Leader) were sent out by the review team. The objective was to evaluate each of the 2011 ongoing research projects in Embrapa in 1990. These were fully examined by Project Leaders. 
Technical Directors and National Program Coordinators analyzed 1737 of these projects. Thirty six research centers, active in 1990, took part in the program. Our definition of a quality index is a function of the responses given in these questionnaires by National Program Coordinators and Technical Directors. With only one exception the quality index thus defined is explained in terms of factor input measures induced by Project Leaders. We now describe the quality aspects considered and the measurement scheme used to quantify and pool them in convenient indices. Eighteen variables of a priori interest to Embrapa were quantified by National Program Coordinators and Technical Directors. The reasons and merits of this particular choice of variables, and in a more general setting, for the choice of all the variables in this study, were the result of intense discussions of specialized personnel within the review team. The list of variables is on Table 1. There, a variable intended to be quantified by National Program Coordinators is indicated by the letter C. A variable intended to be quantified by a Technical Director is indicated by the letter N. Thus, for example, C004 was answered only by National Program Coordinators and N007 only by Technical Directors. The values of each variable are in the range $0-7$. The left extreme (zero) represents "very bad" and the right extreme "very good" in regard to the quality characteristic envisaged by the variable definition.

Table 1

Quality Variables

\begin{tabular}{l|l|l}
\hline Variable & Code & \multicolumn{1}{c}{ Characteristics Whose Intensity Are Being Neasured } \\
\hline C004 & 1 & Adequacy to the permanent objectives of the research center. \\
C005 & 2 & Adequacy to the actual priorities of the research center. \\
C006 & 3 & Understanding of contents from project title. \\
C007 & 4 & Understanding of contents from project abstract. \\
C008 & 5 & Adequacy of strategy to reach project objectives. \\
C009 & 6 & Consideration given to environment and quality of life. \\
C010 & 7 & Consideration given to social economic aspects. \\
N005 & 8 & Adequacy to the actual priorities of the research program. \\
N006 & 9 & Adequacy to the permanent priorities of the research program. \\
N007 & A & Level of precision and amplitude of the research problem. \\
N008 & B & Potential to reach project objectives. \\
N009 & C & Level of linkage from objectives to solution of research problem. \\
N010 & D & Potential to agricutural development. \\
N011 & E & Contribution to scientific progress. \\
N012 & F & Adequacy of hypothesis to objectives. \\
N013 & G & Adequacy of methodology used to test hypothesis. \\
N016 & H & Relevance of problem proposed. \\
N017 & I & Solvability of the problem in terms of project. \\
\hline
\end{tabular}




\section{G. S. SOUZA et al.: ASSESSMENT OF QUALITY IN AGRICULTURAL RESEARCH}

The eighteen quality characteristics as measured by the eighteen quality variables were submitted to an exploratory multivariate analysis via multidimensional scaling This approach revealed the existence of 4 dimensions, or distinct measures of quality - dependent variables, that will serve as a basis for the assessment of different groups of inputs. Our analysis begins with the calculation of Pearson's produc1 moment correlation coefficients. We use those as a measure of similarity between variables. Table 2 shows the correlations quantities involved in this exercise. It is seen that except for a negligible negative correlation between $\mathrm{C} 010$ and N011, the coefficients $r_{\mathrm{ij}}$ are, indeed, a measure of similarity in the sense of Mardia, Bibby, and Kent ${ }^{5}$. The transformation

$$
d_{\mathrm{ij}}=\left(2\left(1-\left|r_{\mathrm{ij}}\right|\right)\right)^{1 / 2}
$$

induces a distance measure that entails a multidimensional scale type analysis. This technique is concerned with the construction of a configuration of the quality variables that allows their representation in a Euclidean space of small dimension. By a configuration we understand the determination of coordinates in such way that proximity in the Euclidean norm sense is equivalent to proximity in the sense of the distance induced by the notion of similarity (quality).

A bidimensional representation (configuration in $R^{2}$ ) of the matrix $\left(d_{\mathrm{ij}}\right)$ is shown in Table 3. It was obtained via PROC ALSCAL (SAS - Sugi library). The variable DIMENSION, with two levels, gives the coordinates of each variable in the representation. Codes are reported in Table 1. A plot of these points is shown in Fig. 1. It resembles a map showing proximities. The representation is very much suggestive. First of all, as expected, there is a clear separation between $\mathrm{C}$ variables and $\mathbf{N}$ variables. Within each of these groups there are two further groups of variables, each, apparently, measuring different characteristics. These four conglomerates are $G_{1}(8,9, E, H, D)$, and $G_{2}(A, B, C, F, G, I)$, on the $N$ side, and $G_{3}(1,2,6,7)$, and $G_{4}(3,4,5)$ on the $C$ side.

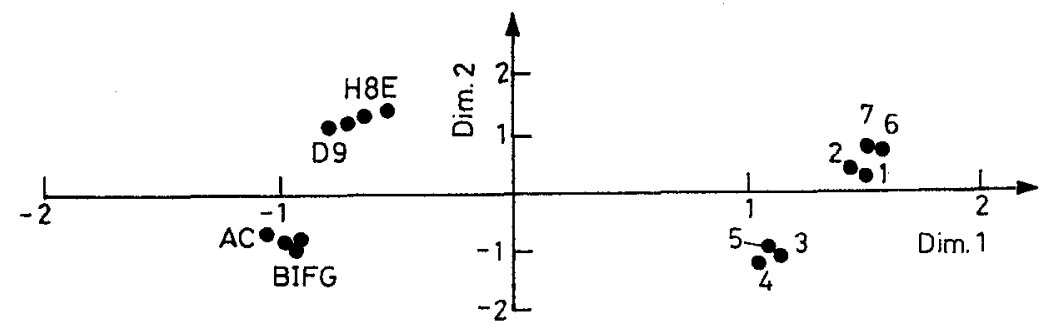

Fig. 1. Configuration in two dimensions 


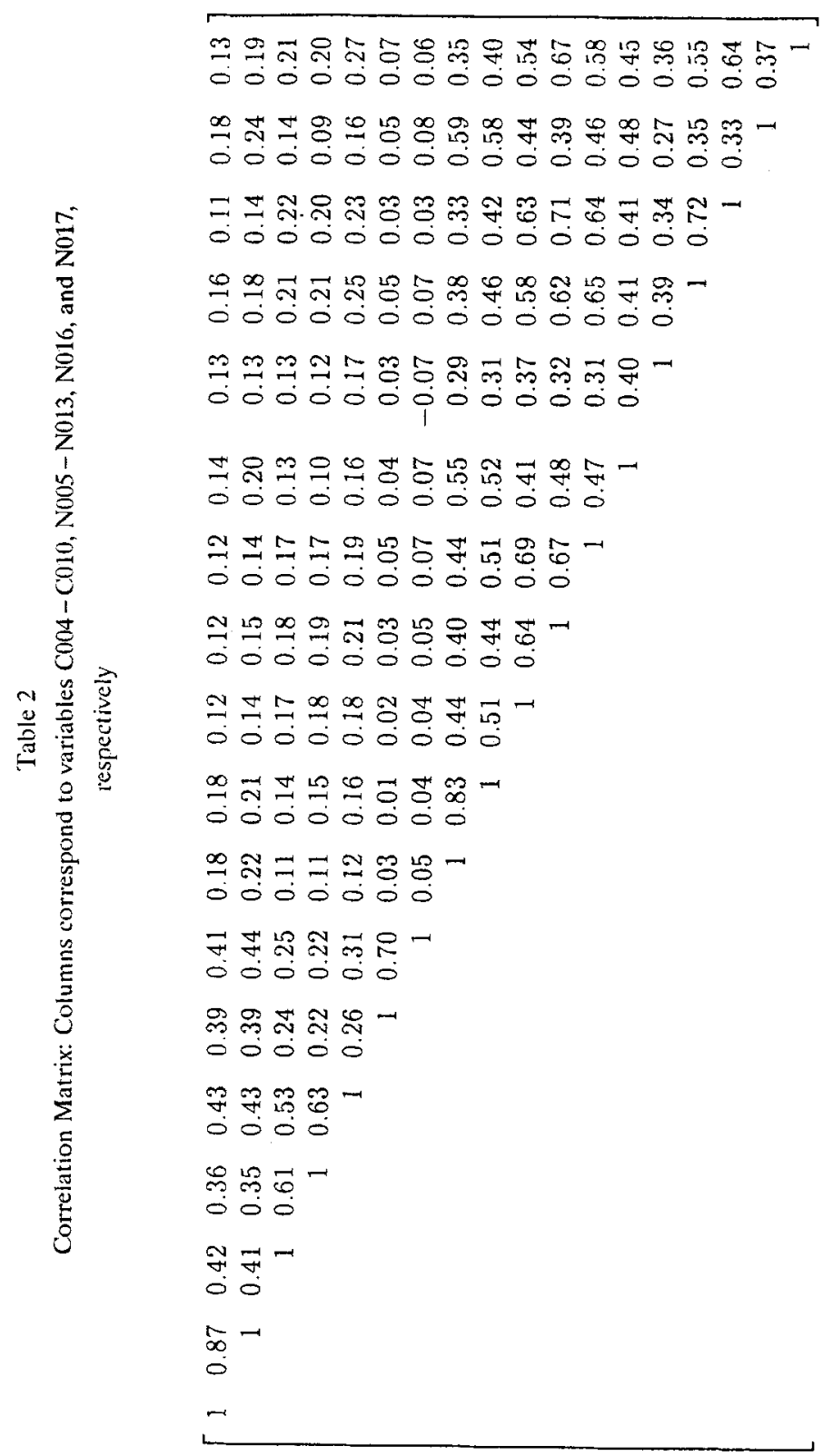


Table 3

Configuration derived in two dimensions

\begin{tabular}{c|c|c}
\hline Code & \multicolumn{2}{|c}{ Dimension } \\
\cline { 2 - 3 } & 1 & 2 \\
\hline 1 & 1.51 & 0.25 \\
2 & 1.43 & 0.35 \\
3 & 1.12 & -1.06 \\
4 & 1.05 & -1.18 \\
5 & 1.09 & -0.99 \\
6 & 1.58 & 0.70 \\
7 & 1.52 & 0.73 \\
8 & -0.65 & 1.24 \\
9 & -0.79 & 1.04 \\
$\mathrm{~A}$ & -1.05 & -0.69 \\
$\mathrm{~B}$ & -0.97 & -0.82 \\
$\mathrm{C}$ & -1.04 & -0.65 \\
$\mathrm{D}$ & -0.79 & 1.07 \\
$\mathrm{E}$ & -0.54 & 1.34 \\
$\mathrm{~F}$ & -0.92 & -0.79 \\
$\mathrm{G}$ & -0.94 & -0.88 \\
$\mathrm{H}$ & -0.70 & 1.16 \\
$\mathrm{I}$ & -0.92 & -0.80 \\
\hline
\end{tabular}

Two measures of goodness of fit for the representation are Kruskal's coefficient of stress $(0.36)$ and the coefficient of determination (0.74). Since Kruskal's coefficient is a bit high we increased the representation to $R^{6}$. Kruskal's coefficient fell to 0.13 and the coefficient of determination increased to 087 . These values are considered to be more reasonable. ${ }^{3}$ A cluster analysis via Ward's method, ${ }^{2}$ of this six dimensional configuration revealed the same structure suggested by the bidimensional analysis in 4 and 2 clusters. The use of Fisher's linear discriminant function, ${ }^{5}$ for the $R^{6}$ data, with the four group structure defined by the bidimensional analysis, did not show any classification errors.

The nature of the variables involved in each quality dimension portrayed by the multidimensional scaling is the basis for interpretation. Group 1 comprises a block of variables that serve to the purpose of validating research projects outside the institution. For this reason we call this dimension External Validity. Group 2 reflects internal demands of the institution. We call it, accordingly, Internal Validity. These two groups are of technical nature. Groups 3 and 4, of more administrative nature, are measuring the political and formal aspects of research projects necessary for 
their acceptance within the bureaucratic clannels of the institution. For this reason we call them Political and Institutional Adequacy and Formal Adequacy, respectively.

As a quality index, within each dimension, we use a weighted average of the type

$$
I=\left(\sum_{i=1}^{n} a_{i} x_{i}\right) /\left(7 \sum_{i=1}^{n} a_{i}\right) \times 100
$$

where $x_{\mathrm{i}}$ represents the value of a quality variable within its respective dimension. The weights

$$
a_{\mathrm{i}}=1 / 1-g_{\mathrm{i}}
$$

are the inverses of the distribution indices $1-g_{\mathrm{i}}$. In this expression the quantity $g_{\mathrm{i}}$ is Gini's concentration index for variable $i{ }^{4}$ This system of weights has some appeal from a quality control point of view. It will give less weight to variables that are controlled in regard to quality, that is, variables whose distribution is uniform. For our particular case the system provides values between $1 / n$, which corresponds to the simple average, and the coefficient of variation.

Table 4 shows averages, standard errors, the values of $g_{\mathrm{i}}$ for each variable, and their relative weights within each quality dimension (column RW).

Of course the same weight system can be used to define a general quality index without any appeal to multidimensional scaling. If $I_{\mathrm{G}}$ represents such an index, it can be shown that

$$
I_{\mathrm{G}}=0.2725 I_{1}+0.3222 I_{2}+0.2427 I_{3}+0.1626 I_{4}
$$

where $I_{1}, I_{2}, I_{3}$, and $I_{4}$ are the quality indices computed for dimensions 1 trough 4 , respectively.

From the expression for $I_{\mathrm{G}}$ it is seen that technical aspects have a higher impact on overall quality, as measured here, than administrative aspects.

Figure 2 shows the descriptive aspects found for the quality indices. All distributions are left skewed. The distributions show concentration on high values. This is a reflection of the excellency of Embrapa's research projects, or, in a more pessimistic view, of the benevolence of the judges. 
Table 4

Statistics for Quality Variables.

RW: Weights in $I_{1}-I_{4}$. RO: Weights in $I_{G}$

\begin{tabular}{cccccc}
\hline Variable & Mean & Std.Err. & $g_{i}$ & RW & RO \\
\hline C004 & 6.20 & 1.24 & 0.09 & 0.22 & 0.05 \\
C005 & 6.03 & 1.39 & 0.11 & 0.23 & 0.06 \\
C006 & 6.32 & 1.03 & 0.08 & 0.33 & 0.05 \\
C007 & 5.96 & 1.11 & 0.10 & 0.33 & 0.05 \\
C008 & 5.78 & 1.26 & 0.11 & 0.34 & 0.05 \\
C009 & 4.53 & 2.17 & 0.26 & 0.27 & 0.07 \\
C010 & 4.52 & 2.19 & 0.27 & 0.28 & 0.08 \\
N005 & 6.48 & 0.98 & 0.06 & 0.19 & 0.05 \\
N006 & 6.39 & 1.05 & 0.07 & 0.19 & 0.05 \\
N007 & 6.18 & 1.03 & 0.08 & 0.17 & 0.05 \\
N008 & 6.11 & 1.03 & 0.08 & 0.17 & 0.05 \\
N009 & 6.41 & 0.85 & 0.06 & 0.16 & 0.05 \\
N010 & 6.04 & 1.16 & 0.09 & 0.20 & 0.05 \\
N011 & 5.17 & 1.74 & 0.18 & 0.22 & 0.06 \\
N012 & 6.07 & 1.08 & 0.09 & 0.17 & 0.05 \\
N013 & 6.06 & 1.07 & 0.09 & 0.17 & 0.05 \\
N016 & 6.23 & 1.11 & 0.08 & 0.20 & 0.05 \\
N017 & 5.69 & 1.33 & 0.12 & 0.17 & 0.06 \\
\hline
\end{tabular}

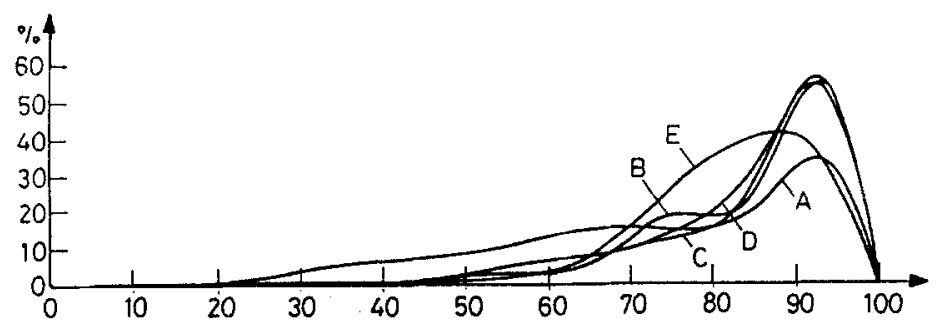

Fig. 2. Frequency distributions: $I_{1}=\mathrm{A}, I_{2}=\mathrm{B}, I_{3}=\mathrm{C}, I_{4}=\mathrm{D}$ and $I_{\mathrm{G}}=\mathrm{E}$

Table 5 shows (the main) Embrapa's research centers classified according to the quality dimensions. As a measure representative of each center we used the median. Intuitively one could expect a negative correlation between the quality variable $\left(I_{\mathrm{G}}\right)$ and the number of projects under supervision of each center. The negative sign was not observed and a significant correlation cannot be reported. 
Table 5

Classification of Embrapa's Research Centers. Decreasing order of $J_{G}$

\begin{tabular}{l|c|c|c|c|c}
\hline Research & $I_{G}$ & $I_{I}$ & $I_{2}$ & $I_{3}$ & $I_{4}$ \\
Center & & & & & \\
\hline NPDIA & 99.21 & 99.99 & 100.00 & 100.00 & 95.24 \\
CNPF & 95.89 & 96.86 & 96.39 & 92.10 & 100.00 \\
CENAR & 95.73 & 99.99 & 97.64 & 92.16 & 95.23 \\
CNPAF & 95.33 & 93.73 & 100.00 & 85.71 & 100.00 \\
CNPUV & 94.33 & 89.68 & 95.15 & 96.05 & 100.00 \\
CNPATB & 93.29 & 90.60 & 95.33 & 100.00 & 100.00 \\
CNPMS & 93.03 & 93.73 & 97.53 & 100.00 & 85.81 \\
CNPBS & 90.60 & 82.99 & 96.39 & 96.05 & 95.14 \\
CNPFT & 89.18 & 79.07 & 83.34 & 100.00 & 100.00 \\
CNPDA & 88.34 & 89.70 & 85.53 & 96.82 & 85.61 \\
DOURAD & 87.38 & 90.89 & 88.10 & 75.87 & 90.48 \\
CNPSA & 87.01 & 99.99 & 92.83 & 60.86 & 95.23 \\
TERE & 86.30 & 81.82 & 88.08 & 84.26 & 85.71 \\
SNLCS & 86.02 & 80.61 & 95.15 & 80.73 & 85.61 \\
CNPT & 85.43 & 94.09 & 88.07 & 72.44 & 85.71 \\
CNPA & 85.40 & 82.54 & 85.72 & 84.99 & 85.70 \\
CNPCa & 85.22 & 91.25 & 85.72 & 84.26 & 90.37 \\
CTAA & 84.65 & 88.08 & 92.77 & 72.16 & 71.13 \\
BVISTA & 84.58 & 83.76 & 80.88 & 81.76 & 95.14 \\
CPAC & 84.57 & 89.83 & 88.19 & 68.52 & 95.14 \\
CPAA & 84.51 & 96.86 & 87.96 & 73.15 & 90.28 \\
CNPC & 82.69 & 85.71 & 95.17 & 63.56 & 71.52 \\
CNPCo & 81.97 & 97.25 & 100.00 & 38.49 & 95.14 \\
CNPO & 81.68 & 88.45 & 88.03 & 66.02 & 80.95 \\
CNPH & 81.24 & 85.66 & 83.31 & 80.34 & 80.85 \\
CNPMF & 80.54 & 83.07 & 83.08 & 75.51 & 83.38 \\
CNPGL & 80.21 & 78.07 & 89.22 & 73.15 & 85.71 \\
CNPGC & 79.57 & 91.14 & 92.77 & 38.49 & 90.37 \\
CNPSA & 79.36 & 85.71 & 85.72 & 52.78 & 90.47 \\
CPATU & 78.92 & 84.95 & 83.35 & 70.67 & 85.71 \\
CPAP & 78.65 & 88.84 & 92.78 & 76.49 & 80.75 \\
BELEM & 78.23 & 81.16 & 78.50 & 67.63 & 73.96 \\
SAOCA & 75.76 & 90.89 & 85.72 & 38.49 & 85.71 \\
CNPAI & 73.75 & 76.18 & 80.77 & 55.65 & 80.85 \\
CPATSA & 72.44 & 85.25 & 78.39 & 59.64 & 61.80 \\
MACAPA & 71.76 & 90.60 & 92.78 & 43.19 & 80.76 \\
\hline & & & & &
\end{tabular}




\section{The assessment of quality}

Of major concern in a research institution is the characterization of the factors of primary influence on the quality of research projects and therefore of research programs. To this end we found necessary to study the nature of the dependencies between the groups of quality indicators and the potential candidate dimensions for factor inputs. We have identified, a priori, the following dimensions, introduced (below) together with the list of respective component variables. The information provided in parenthesis for some of the variables are the codes we use to represent them in the statistical tables they appear. Dimensions (I) through (VII) are evaluated by Project Leaders and Dimension (IX) is evaluated by National Program Coordinators.

\section{Dimension of Direct Impact (I)}

Each variable in this dimension is evaluated only by Project Leaders and assumes values in the range $0-7$. In this scale zero means that the variable does not effect project execution. On the other end, seven means that the variable has a strong influence.

1. Climatic Conditions (P035).

2. Availability of Basic Material (P036).

3. Administrative Support (P037).

4. Coordination Support of National Research Programs (P038).

5. Availability of Physical Resources (P039).

6. Availability of Financial Resources (P040).

7. Availability of Human Resources (P041).

8. Availability of Bibliographical and Information Resources (P042).

9. Errors of Experimental Design (P043).

\section{Dimension of the Influence of Other Institutions (II)}

Each variable in this dimension is a count, i.e., the number of other (than Embrapa) institutions involved in the research project. The information is given by Project Leaders.

1. Other Research Centers in Embrapa (P046).

2. Other State Institutions of Agricultural Research (P047).

3. State Institutions of Agricultural Extension (P048). 
4. Universities (P049).

5. Financing Agencies (P050).

6. Private Enterprises (P051).

7. International Institutions (P053).

8. Organized Groups of Producers (P052).

Dimension of the Influence of Intended Users (III)

Each variable in this dimension is an indicator. If a research project is intended to a given user the value is one, else the value is zero. The variables are not mutually exclusive, i.e., for the same research project, more than one indicator variable will show a value 1 .

1. Farmers (P056).

2. Agricultural Input Industry (fertilizers, seeds, etc.) (P057).

3. Industry of Machinery and Agricultural Implements (P058).

4. Industry of Commercialization of Agricultural Products (P059).

5. Industry of Transformation (P060).

6. Other Researchers (P061).

7. Government Agencies (P062).

Dimension of Geographical Influence (IV)

As in Dimension (III) variables are indicators and not mutually exclusive. A value of one indicates the intended geographical covering for uses of the research output, not the regional origin of a project.

1. Within Brazil (Regions South, Southeast, North, Northeast, and Middle West).

2. Latin America and Caribe.

3. United States and Canada.

4. Europe.

5. Africa.

6. Asia.

7. Oceania.

Dimension of the Influence of the Type of Product Generated (V)

Variables are indicators. Characteristics, as before, may overlap. 
1. Crop Variety and Animal Race (P098).

2. Machinery and Agricultural Implements (P099).

3. Production Technology (P100).

4. Product Processing and Preservation (P101).

5. Agricultural Inputs (fertilizers, seeds, etc.) (P102).

6. Knowledge of Natural Resources (P103).

7. Methods and Research Technology (P104).

8. Technology of Environment Protection (P105).

9. Knowledge of Natural Resources (P106).

10. Knowledge for the Advancement of Science (P107).

Dimension of the Capability of Generating External Budget Resources (VI)

Variables are indicators and characteristics overlap. A value of 1 means that the research project is capable of generating resources from the given source.

1. Private Enterprises.

2. Government.

3. International Organizations.

Dimension of the Intended Diffusion of Research (VII)

Variables are indicators and may overlap.

1. Scientific Articles.

2. Training and Seminars.

3. Technical Reports.

4. Presentation in Congresses.

5. Article intended to be published in Farmer's publications.

Dimension of the Influence of Potential Commercialization (VIII)

We have only one indicator variable in this dimension.

1. Potential sale of final research product.

Dimension of Structural Influence (IX)

All variables in this dimension are categorical and may overlap. A value of one means that the attribute is sufficiently present, and zero otherwise. 
1. Interdisciplinarity.

2. Size (personnel involved).

3. Time devoted by Researchers.

4. Qualification.

The statistical analysis we perform to investigate the impact of these nine dimensions on quality is restricted to main factors. Interactions were disregarded since factors do not cross in a sensible way that allows a clear cut interpretation of interaction effects. An attempt to study interaction effects is shown in Quirino, Cruz and Souza ${ }^{6}$ with the use of contingency tables. In this regard it is worth to mention that the inclusion of interaction terms in some of the regressions we performed with the several quality indices as dependent variables did not show much improvement in the predicitive power of the models. Indeed stepwise methods lead to very low representativity in terms of coefficients of determination as carr be seen in Quirino, Cruz and Souza. ${ }^{6}$

Our approach to investigate the (linear) dependencies between the quality dimensions and Dimension (I) is canonical correlation. Results are shown in Tables 6, 7, and 8. First of all we should say that the dependencies between the two groups are not very strong although significant. However something of practical interest can be said about these dependencies as suggested by the interpretation of two significant canonical correlations $(0.26$ and 0.20$)$ reported in Table 8 . To this end we begin looking at the standardized coefficients of each variable in relation to its specific dimension. On the quality side, the first canonical variate is a contrast dominated by $I_{1}$ and $I_{3}$ (External Validity and Institutional Adequacy). This dominance is also indicated by the correlations of these indices with the first canonical variate (see column 3 in Table 6). Correlations for $I_{1}$ and $I_{3}$ are 0.51 and 0.84 respectively. From the side of the input variables the first canonical variate is an overall index dominated by P035 (Climatic Conditions), P042 (Availability of Bibliographical and Information Resources), P041 (Availability of Human Resources), and P037 (Administrative support). The relation to quality seems to go in opposite directions (less resources more quality). This is revealing. Although these particular input factors may be of importance to quality performance of research projects (see column 3 in Table 7), the indication is that researchers are overcoming, at least in the short run, the difficulties generated by the lack of appropriate levels of those resources. 
Table 6

Quality Variables - Dimension (I)

\begin{tabular}{c|r|r|r|r}
\hline Variable & \multicolumn{2}{|c|}{ Standardized Coefficient } & \multicolumn{2}{c}{ Correlation } \\
\cline { 2 - 5 } & 1st Can. Var. & 2nd Can. Var. & 1st Can. Var. & 2nd Can. Var. \\
\hline$I_{1}$ & 0.67 & -0.31 & 0.51 & -0.44 \\
$I_{2}$ & -0.37 & 0.05 & 0.12 & -0.38 \\
$I_{3}$ & 0.83 & 0.49 & 0.84 & 0.17 \\
$I_{4}$ & -0.01 & -0.95 & 0.27 & -0.84 \\
\hline
\end{tabular}

Table 7

Input Variables - Dimension (I)

\begin{tabular}{l|r|r|r|r|r}
\hline Variable & \multicolumn{2}{|c|}{ Standardized Coefficient } & \multicolumn{2}{|c|}{ Correlation } & \multirow{2}{*}{ Average } \\
\cline { 2 - 5 } & 1st Can. Var. & 2nd Can. Var. & 1st Can. Var. & 2nd Can. Var. & \\
\hline P035 & 0.55 & -0.002 & 0.64 & 0.13 & 1.31 \\
P036 & 0.01 & 0.11 & 0.31 & 0.42 & 1.64 \\
P037 & 0.35 & -0.11 & 0.50 & 0.21 & 0.88 \\
P038 & -0.06 & 0.01 & 0.35 & 0.25 & 0.45 \\
P039 & 0.11 & 0.16 & 0.34 & 0.42 & 1.68 \\
P040 & -0.30 & 0.55 & 0.15 & 0.59 & 2.47 \\
P041 & 0.37 & -0.32 & 0.54 & 0.08 & 2.28 \\
P042 & 0.45 & 0.11 & 0.57 & 0.31 & 0.83 \\
P043 & -0.27 & 0.73 & -0.01 & 0.80 & 0.24 \\
\hline
\end{tabular}

Table 8

Canonical Correlations for Quality vs. Dimension (I)

\begin{tabular}{c|c|c}
\hline Can. Var. & Can. Corr. & p-value \\
\hline 1 & 0.26 & 0.0001 \\
2 & 0.20 & 0.0001 \\
3 & 0.09 & 0.60 \\
4 & 0.05 & 0.77 \\
\hline
\end{tabular}

The second canonical variate, on the quality side, tells us a different story. It is a contrast dominated by $I_{1}$ and $I_{4}$ (External Validity and Formal Adequacy). The greatest influence is that of $I_{4}$ (see columns 2 and 4 of Table 6 ). On the input side the second canonical variate is an overall index dominated by P040 (Availability of Financial Resources), P043 (Errors of Experimental Design), P039 (Availability of Physical Resources), and P036 (Availability of Basic material). The association suggested by the linear variates is inverse, that is, the higher the values of those input variables, indicating substantial lack of resources, the lesser are the actual quality 
indices of the corresponding research projects, in at least one or two of its dimensions. These results seem to pinpoint the crucial input variables necessary to quality improvement. In other words variables that may affect quality in the short and in the long run.

The influence of input Dimension (II) is summarized in Tables 9, 10, and 11. Although significant, as before, there is not a strong association between the input dimension and the quality variables. From the quality side, the first canonical variate is an index dominated by $I_{3}$ (Institutional Adequacy). The second canonical variate is dominated by $I_{1}$ (External Validity). The individual correlations with the quality dimensions tell the same story. From the input side, the first canonical variate is dominated by variables P046 (Other Research Centers in Embrapa), P047 (Other State Institutions of Agricultural Research), P048 (State Institutions of Agricultural Extension), and P051 (Private Enterprises). Here we notice the same difficulties for interpretation discussed in Rencher. ${ }^{9}$ The individual correlations are telling a different story than that told by standardized coefficients. According to the latter, variable P046 has no association with the input dimension, as measured by its first canonical variate. What seems to be the case is that a general increase in P047, P051, and P053 (International Institutions) will more than compensate the negative impact of $\mathrm{P} 046$, producing, in consequence, higher values of $I_{3}$. In other words, the more intense is the involvement of a research project with external institutions, including international groups and private enterprises, the better is the institutional adequacy of the project.

The second canonical variate from the quality side shows a negative strong influence of $I_{1}$ (Internal Validity) and $I_{4}$ (Formal Adequacy). From the input side the canonical variate is dominated by P052 (Organized Groups of Producers). The message here is that the higher is the involvement of a research project with organized groups of producers, the lesser is the quality of this research project in regard to the dimensions of external validity and formal adequacy.

Table 9

Quality Variables - Dimension (II)

\begin{tabular}{c|r|r|r|r}
\hline Variable & \multicolumn{2}{|c|}{ Standardized Coefficient } & \multicolumn{2}{|c}{ Correlation } \\
\cline { 2 - 5 } & 1st Can. Var. & 2nd Can. Var. & 1st Can. Var. & 2nd Can. Var. \\
\hline$I_{1}$ & 0.16 & -1.17 & 0.38 & -0.78 \\
$I_{2}$ & 0.32 & 0.75 & 0.44 & -0.06 \\
$I_{3}$ & 0.93 & 0.21 & 0.90 & 0.07 \\
$I_{4}$ & -0.24 & -0.37 & 0.18 & -0.31 \\
\hline
\end{tabular}


Table 10

Input Variables - Dimension (II)

\begin{tabular}{c|r|r|r|r|c}
\hline Variable & \multicolumn{2}{|c|}{ Standardized Coefficient } & \multicolumn{2}{|c|}{ Correlation } & \multirow{2}{*}{ Average } \\
\cline { 2 - 5 } & 1st Can. Var. & 2nd Can. Var. & 1st Can. Var. & 2nd Can. Var. & \\
\hline P046 & -0.63 & -0.45 & 0.04 & 0.10 & 0.76 \\
P047 & 0.74 & 0.08 & 0.75 & 0.04 & 0.51 \\
P048 & 0.56 & 0.66 & 0.19 & 0.29 & 0.26 \\
P049 & 0.03 & -0.01 & 0.07 & 0.11 & 0.43 \\
P050 & 0.01 & -0.08 & 0.05 & -0.05 & 0.17 \\
P051 & 0.61 & -0.45 & 0.55 & 0.18 & 0.43 \\
P052 & -0.25 & 1.08 & 0.16 & 0.83 & 0.30 \\
P053 & 0.17 & -0.23 & 0.37 & -0.19 & 0.46 \\
\hline
\end{tabular}

Table 11

Canonical Correlations for Quality vs. Dimension (II)

\begin{tabular}{c|c|c}
\hline Can. Var. & Can. Corr. & p-value \\
\hline 1 & 0.19 & 0.0001 \\
2 & 0.15 & 0.001 \\
3 & 0.10 & 0.32 \\
4 & 0.03 & 0.93 \\
\hline
\end{tabular}

Dimension (III) is categorical and is analysed in Table 12. There (and in similar subsequent tables) we present averages, proportions of projects falling in each category, and a p-value corresponding to an analysis of variance test of the quality dimension relative to a treatment with two levels. Level 1 indicates the presence of a given input variable. Level 0 indicates its absence. We emphasize here that such comparison is the study of the difference between two means: one associated with projects having a certain characteristic (level 1) and another associated with all projects lacking the same characteristic (level 0 ). Notice that since the categories listed in the tables overlap a direct comparison of a given pair of characteristics is not feasible. The column of proportions gives the intensity of projects in each category. We should also notice that due to the overlap of categories the sum of these proportions is not one.

Not many significant results were found in the ANOVA outputs of Dimension (III). In regard to the overall quality index $I_{\mathrm{G}}$ only P059 (Industry of Transformation) and P061 (Other researchers), significantly, seem to cause positive effects. It is worth to mention the significant results for $I_{3}$ of P058 (Industry of Machinery and Agricultural Implements) and P062 (Government Agencies). 


\section{G. S. SOUZA et al:: ASSESSMENT OF QUALITY IN AGRICULTURAL RESEARCH}

Table 12

Analysis of Input Dimension (III).

Values within (.) are p-values. $\mathrm{A}+(-)$ indicates significantly higher (lower) than the mean response for all other projects (not shown)

\begin{tabular}{c|c|c|c|c|c|c}
\hline Variable & $I_{1}$ & $I_{2}$ & $I_{3}$ & $I_{4}$ & $I_{G}$ & Prop. \\
\hline P056 & 86.90 & 86.91 & 74.62 & 87.11 & 83.84 & 74.9 \\
& $(0.94)$ & $(0.29)$ & $(0.29)$ & $(0.31)$ & $(0.55)$ & \\
P057 & 87.67 & 88.26 & 74.57 & 88.46 & 84.78 & 17.2 \\
& $(0.23)$ & $(0.07)$ & $(0.89)$ & $(0.03)$ & $(0.09)$ & \\
P058 & 85.17 & 86.45 & +78.56 & 87.51 & 83.89 & 7.4 \\
& $(0.11)$ & $(0.60)$ & $(0.02)$ & $(0.64)$ & $(0.99)$ & \\
P059 & 87.23 & 87.84 & +78.16 & 86.68 & +85.13 & 15.0 \\
& $(0.65)$ & $(0.28)$ & $(0.001)$ & $(0.70)$ & $(0.04)$ & \\
P060 & 86.88 & 88.10 & 74.91 & 86.90 & 84.51 & 22.8 \\
& $(0.96)$ & $(0.07)$ & $(0.58)$ & $(0.91)$ & $(0.19)$ & \\
P061 & +87.22 & +87.33 & 74.60 & 87.19 & +84.13 & 78.2 \\
& $(0.01)$ & $(0.03)$ & $(0.38)$ & $(0.11)$ & $(0.03)$ & \\
P062 & 86.69 & 87.08 & +75.40 & 86.77 & 83.98 & 48.2 \\
& $(0.47)$ & $(0.92)$ & $(0.05)$ & $(0.55)$ & $(0.78)$ & \\
\hline
\end{tabular}

Table 13

Analysis of Input Dimension (IV) - Within Brazil.

Values within (.) are p-values. $A+(-)$ indicates significantly higher (lower) than the mean response for all other projects (not shown)

\begin{tabular}{c|c|c|c|c|c|c}
\hline Variable & $I_{1}$ & $I_{2}$ & $I_{3}$ & $I_{4}$ & $I_{G}$ & Prop. \\
& & & & & & \\
\hline Middle West & +88.06 & +88.21 & +77.51 & +89.49 & +85.75 & 62.0 \\
& $(0.0001)$ & $(0.0001)$ & $(0.0001)$ & $(0.0001)$ & $(0.0001)$ & \\
South & +87.23 & +87.54 & -73.38 & +87.15 & 84.00 & 58.5 \\
& $(0.02)$ & $(0.03)$ & $(0.04)$ & $(0.003)$ & $(0.12)$ & \\
North & 86.97 & 87.23 & -72.65 & -85.32 & 83.31 & 41.5 \\
& $(0.15)$ & $(0.27)$ & $(0.0001)$ & $(0.002)$ & $(0.12)$ & \\
Northeast & +87.39 & +87.49 & 73.77 & +86.95 & +84.00 & 69.5 \\
& $(0.0001)$ & $(0.01)$ & $(0.15)$ & $(0.004)$ & $(0.04)$ & \\
Southeast & +87.40 & +87.58 & +75.55 & +87.84 & +84.57 & 73.8 \\
& $(0.0001)$ & $(0.001)$ & $(0.0001)$ & $(0.0001)$ & $(0.0001)$ & \\
\hline
\end{tabular}

Table 13 shows the analysis carried out for input Dimension (IV) (in the same spirit of Dimension (III)). The Middle West and Southeast dominate $I_{\mathrm{G}}$ the overall 
quality index. Then follows South and Northeast on almost equal footing. The worst results are for the North region. The reason for the overall weak result in the North is mainly related to quality indices $I_{3}$ and $I_{4}$. Since these dimensions are of more administrative nature, the evidence is that the research that contemplates the North region is definitely not satisfactory relatively to formal requirements. We notice also some weaknesses in more technical aspects.

Projects are more intense covering the Southeast, Middle West, and North-east.

On the international scale, Table 14, research projects intended to cover the United States and Canada, Europe, and Oceania, are best. United States and Canada, and Europe show also more intensity. Performance at the international geographical dimension is better than within Brazil. It seems rather odd that the intensities for Latin America and Africa are substantially lower than the others.

Table 14

Analysis of Input Dimension (IV) - International.

Values within (.) are p-values. $A+(-)$ indicates significantly higher (lower) than the mean response for all other projects (not shown)

\begin{tabular}{c|c|c|c|c|c|c}
\hline Variable & $I_{1}$ & $I_{2}$ & $I_{3}$ & $I_{4}$ & $I_{G}$ & Prop. \\
& & & & & & \\
\hline Asia & +88.68 & 88.16 & 76.66 & +88.68 & +85.60 & 62.0 \\
& $(0.02)$ & $(0.17)$ & $(0.06)$ & $(0.01)$ & $(0.001)$ & \\
Latin America & +88.21 & +88.00 & +76.29 & +88.46 & +85.18 & 58.5 \\
& $(0.0001)$ & $(0.01)$ & $(0.001)$ & $(0.0001)$ & $(0.0001)$ & \\
US and Canada & +89.13 & +88.84 & +81.52 & +90.0004 & +87.06 & 41.5 \\
& $(0.003)$ & $(0.03)$ & $(0.0001)$ & $(0.0001)$ & $(0.0001)$ & \\
Europe & 87.57 & +89.35 & +81.93 & +90.11 & +86.53 & 69.5 \\
& $(0.40)$ & $(0.04)$ & $(0.0001)$ & $(0.0002)$ & $(0.002)$ & \\
Oceania & +89.60 & +90.02 & +79.25 & +90.18 & +87.22 & 73.8 \\
& $(0.01)$ & $(0.01)$ & $(0.001)$ & $(0.001)$ & $(0.0001)$ & \\
Africa & +88.48 & +88.47 & 75.88 & +87.25 & +85.26 & 73.8 \\
& $(0.001)$ & $(0.01)$ & $(0.07)$ & $(0.13)$ & $(0.001)$ & \\
\hline
\end{tabular}

The effect of input Dimension (V) is shown in Table 15. The best research projects are those generating Agricultural Inputs (P102). Next follows those in the category of Crop Varieties and Animal Races (P098), Methods and Research Technology (P104), and Environment Protection Technology (P105). The worst results are for research projects in Product Processing and Preservation (P101) and Agricultural Implements (P099). It is interesting to notice here that research projects intended to advance scientific knowledge (P107) do not dominate the overall quality 
index $I_{\mathrm{G}}$. Compared to all other projects the category shows a mean significantly higher only in $I_{1}$ (External Validity). The highest intensities of project participation are on Production of Technologies (P100), Methods and Research Technology (P104), and Crop Varieties and Animal Races (P098).

Table 15

Analysis of Input Dimension (V).

Values within (.) are p-values. $\mathrm{A}+(-)$ indicates significantly higher (lower) than the mean response for all other projects (not shown)

\begin{tabular}{c|c|c|c|c|c|c}
\hline Variable & $I_{1}$ & $I_{2}$ & $I_{3}$ & $I_{4}$ & $I_{G}$ & Prop. \\
& & & & & & \\
\hline P098 & +89.21 & +88.64 & 75.47 & +88.501 & +85.46 & 28.1 \\
& $(0.0001)$ & $(0.002)$ & $(0.17)$ & $(0.003)$ & $(0.0001)$ & \\
P099 & 85.88 & 86.54 & 78.05 & -81.71 & 82.67 & 2.3 \\
& $(0.61)$ & $(0.82)$ & $(0.28)$ & $(0.02)$ & $(0.47)$ & \\
P100 & 86.65 & 86.66 & 73.67 & 87.22 & 83.47 & 45.5 \\
& $(0.37)$ & $(0.20)$ & $(0.14)$ & $(0.51)$ & $(0.07)$ & \\
P101 & 84.80 & 85.49 & 73.84 & -82.51 & 82.18 & 6.4 \\
& $(0.09)$ & $(0.24)$ & $(0.76)$ & $(0.001)$ & $(0.10)$ & \\
P102 & 87.85 & 87.77 & +78.89 & +90.40 & +86.06 & 11.6 \\
& $(0.27)$ & $(0.41)$ & $(0.001)$ & $(0.0001)$ & $-(0.002)$ & \\
P103 & 87.61 & 87.42 & 74.33 & 86.44 & 83.80 & 22.3 \\
& $(0.23)$ & $(0.55)$ & $(0.93)$ & $(0.42)$ & $(0.83)$ & \\
P104 & 87.18 & 87.17 & +77.73 & +88.87 & +85.10 & 33.5 \\
& $(0.51)$ & $(0.77)$ & $(0.0001)$ & $(0.0001)$ & $(0.0003)$ & \\
P105 & 88.01 & 87.12 & +79.62 & 86.38 & +85.31 & 19.0 \\
& $(0.09)$ & $(0.92)$ & $(0.0001)$ & $(0.39)$ & $(0.01)$ & \\
P106 & +84.19 & 85.52 & +78.31 & 87.20 & 83.72 & 11.2 \\
& $(0.001)$ & $(0.08)$ & $(0.01)$ & $(0.08)$ & $(0.80)$ & \\
P107 & +88.22 & 87.34 & 75.01 & 87.49 & 84.50 & 29.3 \\
& $(0.003)$ & $(0.52)$ & $(0.42)$ & $(0.29)$ & $(0.10)$ & \\
\hline
\end{tabular}

The study of the impact of input Dimension (VI) is on Table 16. In regard to average of $I_{\mathrm{G}}$ values there is not a clear dominance, although Private Enterprises and Government have significantly higher averages when contrasted with all other possibilities, respectively. The influence of the input dimension on quality, in this context, is pretty much uniform. It should be noticed here the high values of External Validity $\left(I_{2}\right)$ for research projects with substantial potential to obtain resources of international organizations. 


\section{G. S. SOU\%A et al.: ASSISSSMINI' OF QUALITY IN AGRICULTURAL RESEARCH}

Table 10

Analysis of Input Dimension (V1).

Values within (.) are p-values. $A+(-)$ indicates significantly higher (lower) than the mean response for all other projects (not shown)

\begin{tabular}{c|c|c|c|c|c|c}
\hline Variable & $I_{1}$ & $I_{2}$ & $I_{3}$ & $I_{4}$ & $I_{G}$ & Prop. \\
& & & & & & \\
\hline Private Enterpr. & +87.74 & +87.59 & +76.38 & 87.32 & +84.95 & 40.0 \\
& $(0.02)$ & $(0.13)$ & $(0.001)$ & $(0.35)$ & $(0.0002)$ & \\
Government & 87.28 & +87.64 & +75.64 & 87.30 & +84.51 & 47.6 \\
& $(0.23)$ & $(0.07)$ & $(0.01)$ & $(0.31)$ & $(0.02)$ & \\
Intern. Organi. & +88.29 & 86.99 & 75.76 & 86.87 & 84.53 & 41.5 \\
& $(0.002)$ & $(0.91)$ & $(0.06)$ & $(0.84)$ & $(0.10)$ & \\
\hline
\end{tabular}

In the statistical analysis of input Dimension (VII) (see Table 17), only Technical Reports does not show, systematically, higher averages, when contrasted with all others (actually averages are higher for $I_{4}$ ). The influence is dominated by Scientific Articles, Presentation in Congresses, and Training and Seminars. The highest intensities are Scientific Articles and Presentation in Congresses (each with more than $70 \%$ of all research projects). This seems to be an indication that Embrapa is a research company much more engaged in the solution of problems devoted to scientific knowledge than to agribusiness.

\section{Table 17}

Analysis of Input Dimension (VII).

Values within (.) are p-values. $\mathrm{A}+(-)$ indicates significantly higher (lower) than the mean response for all other projects (not shown)

\begin{tabular}{c|c|c|c|c|c|c}
\hline Variable & $I_{1}$ & $I_{2}$ & $I_{3}$ & $I_{4}$ & $I_{G}$ & Prop. \\
\hline Articles & +87.32 & +87.41 & 74.54 & 87.18 & +84.17 & 74.2 \\
& $(0.001)$ & $(0.002)$ & $(0.59)$ & $(0.09)$ & $(0.004)$ & \\
Train. \& Semi. & +87.52 & 87.44 & +75.45 & +87.90 & +85.00 & 64.6 \\
& $(0.002)$ & $(0.05)$ & $(0.002)$ & $(0.0001)$ & $(0.0001)$ & \\
Tech. Reports & 87.06 & 87.27 & 74.61 & +87.50 & 84.02 & 68.8 \\
& $(0.38)$ & $(0.20)$ & $(0.50)$ & $(0.004)$ & $(0.39)$ & \\
Congressses & +87.54 & +87.65 & 74.86 & +87.48 & 84.40 & 71.1 \\
& $(0.0001)$ & $(0.0001)$ & $(0.09)$ & $(0.001)$ & $(0.0001)$ & \\
Producer Public. & 87.24 & 87.42 & 74.68 & +87.70 & +84.29 & 11.6 \\
& $(0.13)$ & $(0.11)$ & $(0.47)$ & $(0.002)$ & $(0.03)$ & \\
\hline
\end{tabular}


Research projects with selling possibilities (Table 18) show more average quality than all others. It is interesting to observe that the dimensions responsible for this significance are of technical rather than of administrative nature.

Table 18

Analysis of Input Dimension (VIII).

Values within (.) are p-values. A + (-) indicates significantly higher (lower) than the mean response for all other projects (not shown)

\begin{tabular}{c|c|c|c|c|c|c}
\hline Variable & $I_{1}$ & $I_{2}$ & $I_{3}$ & $I_{4}$ & $I_{G}$ & Prop. \\
& & & & & & \\
\hline Potential Sale & +87.75 & 87.53 & 75.35 & 87.53 & +84.69 & 43.0 \\
& $(0.03)$ & $(0.35)$ & $(0.10)$ & $(0.18)$ & $(0.01)$ & \\
\hline
\end{tabular}

In the dimension of structural influence the items of real importance are Interdisciplinarity and Qualification. Size is of the least importance. It may even effect quality negatively. Results are on Table 19.

Table 19

Analysis of Input Dimension (IX).

Values within (.) are p-values. $\mathrm{A}+(-)$ indicates significantly higher (lower) than the mean response for all other projects (not shown)

\begin{tabular}{c|c|c|c|c|c}
\hline Variable & $I_{1}$ & $I_{2}$ & $I_{3}$ & $I_{4}$ & $I_{G}$ \\
& & & & & \\
\hline Interdiscip. & +86.46 & +88.25 & +77.59 & +89.24 & +85.46 \\
& $(0.58)$ & $(0.0001)$ & $(0.0001)$ & $(0.0001)$ & $(0.0001)$ \\
Size & -85.69 & 87.04 & 75.11 & +87.30 & 83.58 \\
& $(0.01)$ & $(0.17)$ & $(0.22)$ & $(0.0001)$ & $(0.69)$ \\
Time & 86.27 & +87.25 & 74.15 & +87.48 & 83.91 \\
& $(0.70)$ & $(0.01)$ & $(0.76)$ & $(0.0001)$ & $(0.08)$ \\
Qualification & 86.49 & +87.45 & +75.77 & +88.15 & +84.64 \\
& $(0.26)$ & $(0.0001)$ & $(0.0001)$ & $(0.001)$ & $(0.03)$ \\
\hline
\end{tabular}

Of particular importance to the administration of Embrapa is the performance of a research project as measured by the percentage of tasks accomplished, until the moment of the review, relative to all tasks programmed in the planning stage of the project (P138). Also of importance is the percentage of total actions planed that indeed can be achieved within the time span actually assigned to a research project (P139). In the past, Embrapa has used these two measures to evaluate its research 


\section{G. S. SOUZA et al:: ASSESSMENT OF QUALITY IN AGRICULTURAL RESEARCH}

projects. See Quirino, Cnız, and Souza ${ }^{6}$ and Quirino and Borges-Andrade 8 for more details on this matter.

Without assuming any a priori causal relationship between quality and performance in the context above, we studied the association between the relevant variables via canonical correlation. Only one pair of canonical variates is enough to describe the nature of the linear dependency between quality and performance. The value of the canonical correlation is 0.24 , significantly different from zero but not very intense. On the performance side the canonical variate is dominated by P139. On the quality side the index is dominated by $I_{2}$ (Internal Validity) and $I_{4}$ (Formal Adequacy), defining a mixture or compound of technical and administrative aspects. Tables 20, 21, and 22 show these results.

Table 20

Quality Variables - Performance

\begin{tabular}{c|r|r|r|r}
\hline \multirow{2}{*}{ Variable } & \multicolumn{2}{|c|}{ Standardized Coefficient } & \multicolumn{3}{c}{ Correlation } \\
\cline { 2 - 5 } & 1st_Can. Var. & 2nd Can. Var. & 1st Can. Var. & 2nd Can. Var. \\
\hline$I_{1}$ & -0.18 & -0.77 & 0.41 & -0.50 \\
$I_{2}$ & 0.77 & 0.37 & 0.84 & -0.04 \\
$I_{3}$ & -0.14 & 0.84 & 0.11 & 0.77 \\
$I_{4}$ & 0.59 & -0.12 & 0.75 & 0.10 \\
\hline
\end{tabular}

Table 21

Performance Variables

\begin{tabular}{c|r|r|r|r}
\hline Variable & \multicolumn{2}{|c|}{ Standardized Coefficient } & \multicolumn{2}{c}{ Correlation } \\
\cline { 2 - 5 } & 1st Can. Var. & 2nd Can. Var. & 1st Can. Var. & 2nd Can. Var. \\
\hline P138 & 0.10 & -1.16 & 0.58 & -0.82 \\
P139 & 0.95 & 0.67 & 0.997 & 0.08 \\
\hline
\end{tabular}

Table 22

Canonical Correlations for Quality vs. Performance

\begin{tabular}{c|c|c}
\hline Can. Var. & Can. Corr. & p-value \\
\hline 1 & 0.24 & 0.0001 \\
2 & 0.04 & 0.52 \\
\hline
\end{tabular}




\section{Summary and conclusions}

The multivariate analysis of score data on quality characteristics measured by National Program Coordinators and Technical Directors in Embrapa reveals four quality dimensions. External Validity, Internal Validity, Institutional Adequacy, and Formal Adequacy. External Validity and Internal Validity are indices of technical nature while Institutional Adequacy and Formal Adequacy are of administrative nature. The indices are weighted averages of scores. The weight system is defined with the use of Gini's concentration indices. In general scores measuring Institutional Adequacy are substantially lower than those of any other quality dimension. Nine input dimensions are investigated in an attempt to identify causes of quality. The input dimension of direct impact comprises nine characteristics (climatic conditions, availability of financial, human, physical, and information resources, appropriate coordination, basic material, and errors in design). Availability of financial and physical resources as well as basic material and errors in experimental design seem to be the key issues determining quality. Involvement of research projects with external institutions tend to improve their Institutional Adequacy. Involvement with organized groups of producers on the other side tend to decrease quality level, specifically in its dimensions of External Validity and Formal Adequacy. Research projects intended to the transformation industry and other researchers have significant more overall quality than all others. The geographical input dimension indicates that, within Brazil, the Middle West, relates to higher quality levels in all its dimensions. The North region shows weak results, particularly in the administrative aspects of quality. On an international scale, projects whose results may apply to the United States, Canada, Europe, and Oceania are significantly superior and dominate the overall geographical dimension (including regional Brazil). The dimension of type of product generated indicates a dominance of agricultural inputs followed by crop varieties and animal races, and environment protection technologies. Relatively low quality averages are observed for agricultural implements and product processing technologies. Research intended to advance scientific knowledge does not dominate overall quality. Private enterprises seem to have a high impact on quality as well as other government agencies. Research projects with potential to attract external financing also show high quality levels, specially in the dimension of External Validity. On the diffusion dimension quality is positively influenced by the intention to publish scientific articles, to present results in congresses, seminars, and in training programs. Ouality is also higher, on average, for projects whose research products 


\section{G. S. SOUZA et al.: ASSESSMENT OF QUALITY IN AGRICULTURAL RESEARCH}

show potential for commercialization. Interdisciplinarity and Qualification are important factors (rather than Size and Time) affecting quality and dominate the input dimension of structural influence. Performance, measured by the proportion of tasks, originally planned, that indeed can be finished within the planned time span scheduled for the project, has a low, but significant, positive association with quality. The quality dimensions of importance in this context are Internal Validity and Formal Adequacy.

\section{References}

1. K. J. ALbert, The Strategic Management Handbook, McGraw Hill, New York, 1983.

2. B. S. EverTT, Cluster Analysis, Heineman Educational Books, London, 1980.

3. A. R. Johnson, D. W. Wichern, Applied Multivariate Statistical Analysis, 2nd edition, Prentice Hall, New Jersey, 1988.

4. M. Kendall, A. Stuart, The Advanced Theory of Statistics, Vol 1. Macmillan, New York, 1977.

5. K. V. MARDIA, J. M. BibBY, J. T. KenT, Multivariate Analysis, Academic Press, New York, 1979.

6. T. R. Quirino, E. R., Cruz, G. SouzA, "O Processo de Produção de Conhecimento em Organizaçóes de Pesquisa Agropecuária: Diagnóstico de Projetos". Unpublished manuscript. Embrapa-Sea, 1992a.

7. T. R. Quirino, E. R. Cruz, G. SouzA, "Project Performance and Evaluation in Agricultural Research Organizations". Unpublished manuscript. Embrapa-Sea, $1992 b$.

8. T. R. Quirino, J. HAGE, J. E. Borges-ANDRAL , "Report on the Impact of Human Capital on the Effectiveness of Agricultural Research Centers". Unpublished manuscript. University of Maryland, Center for Innovation Studies in Organizational Design, Entrepreneurship, and Strategic Management, 1985.

9. A. C. RENCHER, Interpretation of canonical discriminant functions, canonical variates, and principal components. The American Statistician, 46 (1992) 217-225. 